\title{
Who Make Effective Teachers, Men or Women? An Indian Perspective
}

\author{
Dr. Fatima Islahi* ${ }^{*}$ Dr. Nasreen \\ Department of Education, Aligarh Muslim University, Aligarh - 202 002, India \\ *Corresponding Author: fatima.islahi@gmail.com
}

Copyright (C) 2013 Horizon Research Publishing All rights reserved.

\begin{abstract}
The article aims to discuss the effectiveness of male and female teachers in relation to demographic factors like marital status, training, location and medium of instruction. These issues have important implications to understand and evaluate teachers' effectiveness especially in view of the changing sex ratio of school teachers. Correlation, t-test, and ANOVA were employed on a sample of 482 teachers comprising 245 males and 237 females. Overall, male and female teachers exhibited insignificantly different effectiveness however variations were noticed with respect to different demographic factors. The paper concludes by arguing that since the quality of education being delivered, generally, has been considered as a function of teachers' degree of effectiveness, there is a need for both substantive and methodological focus on gender specific responsibilities and requirements, in order to take out maximum from male and female teachers to produce high degree of effectiveness in their profession.
\end{abstract}

Keywords Gender, Location, Marital Status, Medium of Instruction, Teachers' Effectiveness, Training

\section{Introduction}

In the present global educational scenario, schools are expected to provide more information on their educational qualities of which the effective teachers form the central and integral component. This becomes pertinent in view of the recent developments in education, such as increased budgetary freedom of schools, demanding and active parents or students, government policies with respect to accountability and accreditation, the development and implementation of standards of teaching/education and publication of rating of school performance in newspapers and on the internet. The importance of a teacher in the educational process is unquestionable. No educational system can rise above the level of its teachers and teachers can either make or mar the society [1]. According to Golla and de Guzman [2], "the teachers form the single strong causal factor in defining the quality of education in schools."
The quality of education being delivered is a function of the teacher's degree of effectiveness [3]. Hanushek [4] showed that if a student had an effective teacher, as opposed to an average teacher, for only five years in a row, the increased learning would be sufficient to close entirely the average gap between low and middle income students during that relatively short amount of time. It is an established fact that effective teachers increase student learning and also the most important school-related factor influencing student achievement.

Teacher effectiveness is an issue that has received increased attention in recent years [5]. Teaching is not restricted to lecturing, instead teachers are expected to motivate, inspire, explain, engage, understand and guide the students for their all round development. Teachers are expected to attract students towards content, concepts, attitudes, values, knowledge and skills under the set frame of pre-determined goals. They are also expected to possess professional proficiency, educational efficiency and social sufficiency. Teacher effectiveness can be said as the power to realize socially valued objectives agreed for teachers' work, especially, but not exclusively, the work concerned with enabling students to learn. It has become an adage that the effectiveness of education is very much dependent on the effectiveness of its teachers.

The need for developing and attaining standards of effectiveness has increased for all teachers in today's competitive teaching environment. A number of studies have focused on various aspects of the teaching profession $[6,7]$ identifying the functions of a teacher [8] or focused on the effective ways of teaching [9] and studied the changing nature of teacher's professionalism [10]. Effectiveness of secondary school teachers may be determined by several factors that influence their job performance. Among these factors, gender is of interest to the general populace especially now that females are gradually taking over and dominating the teaching profession at secondary levels of education. Teachers need to have a complex set of skills, insight, intelligence, knowledge, management, competence, dynamism, and diligence, to meet the challenges of the classroom. While both men and women teachers appear to possess these traits yet they may meet the challenges 
differently. Relationship between gender and teaching has been one of the most interesting aspects for research in the recent past. Impact of gender on teachers' effectiveness has been reported with mixed results. Male and female teachers may behave differently in the classroom [11], and students may react differently to their teachers' behaviours [12-14].

It is quite possible that what appear to be gender differences might, instead, be different teaching styles. Gendered influence of teachers might be related to differences in teaching styles. Female teachers were reported to be more supportive, expressive [15-17], nurturing [18], informal and open toward students [19, 20], spend significantly greater proportion of time encouraging and allowing student participation [16, 21], involve students in peer collaboration [22], believed in flexible teaching methods [20], asked more referential questions, gave more compliments and used less directive forms[17], shared authority and maintained control in the classroom in a way that keeps their relationships with students intact [21]. Male teachers, however, tended to be dominating, exacting and exercised greater control [18-20], emphasised more to the group work and structured activities [20], asked more display questions that made the exchanges between teacher and students shorter but more frequent [17, 23], used their authority at the cost of involvement by students with an authoritarian and task oriented teaching style $[15,21,22,24]$. Researchers also found that male teachers typically lecture for the majority of each class session while female faculty members are more likely to engage students with active and collaborative learning approaches, which are classified as learner-centred instructional practices [25-29]. This may be due to the fact that there are fundamental differences between men's and women's ways of communicating, where a man's world focuses on competition, status, and independence, a woman's world focuses on intimacy, consensus, and interdependence [30].

Marchbanks [31], reported females to generally possess the personality traits necessary to become an effective teacher to a higher degree than males did. On the other hand, Smith [32] found that gender had little influence on how often technical college faculty used the various instructional practices. When controlling for academic school, gender differences were found to be no longer significant by Starbuck [25]. Although there are differences in teaching styles between men and women [15-25], there are many similarities [33-35]. In their extensive reviews of the relevant literature, Brophy [36] and Meece [37] indicated only minor differences in the behaviour of male and female teachers in the classroom that the authors considered a consequence of the gender-typed differences in the behaviour of students themselves.

Students distinguished same teaching style or behaviour differently when displayed by female and male teachers $[13,14,21,38-40]$. This may be because they may hold biased perceptions of the differences between men and women faculty in ways that are consistent with stereotypically gendered expectations of communication and interactive patterns [41-44]. Kite [44] goes on to provide evidence that strong cultural conditioning on gender roles consciously and subconsciously has an influence. Female teachers are apparently expected to exude more warmth and nurturing qualities, yet at the same time such behaviour may be interpreted as weakness and feminine [45]. However, a strong female teacher may be seen as rigid and controlling rather than intellectually rigorous and challenging [30]. Sprague and Massoni, [46] showed that there was greater hostility toward women than toward men who did not meet students' gender-role expectations. Studies also show that students perceive female teachers to be better in traditionally female disciplines (e.g., home economics) as compared to females in traditionally male disciplines like physics and engineering [47]. However, the study by Tieman and Rankin-Ullock [48] suggests that teachers in non-traditional career areas (e.g., men in liberal arts and women in business) are perceived as better because they have succeeded in unexpected areas, based on their gender.

There are also reports of gender biased perception of students by their teachers. Mullola et al. [49] found that male teachers perceived boys more positively and more capable in educational competence and teachability than females. They were also stricter regarding their perceptions of girls' traits. However, Hopf \& Hatzichristou [50] reported female teachers evaluated more positively boys' interpersonal behaviour and assessed children's adjustment as less problematic regarding various aspects of their academic and psychosocial functioning as compared to their male colleagues. Kelly [51] observed that male teachers direct substantially less of their classroom interaction to girls than do female teachers. This was particularly true for feedback, praise and criticism where male teachers virtually ignore their female pupils. As regards teacher's gender, whether male and female teachers interact differently with male and female pupils, the meta-analysis could not arrive at a definite conclusion. Canada and Pringle [52] maintained that male and female teachers negotiate their authority in different ways in a mixed sex classroom, but behave quite similarly in a single sex classroom. They observed that "female-led, mixed-sex classes were more teacher driven and were less student driven than were male-led, mixed-sex classes. And in all female classes, the female teachers behave more male-like and the male teachers behave more female-like.

It becomes evident that gender affects in various complicated and interrelated ways the perceptions and behaviour of teachers and students in an educational setting. Since gender differences are not consistent across several areas of research interest, and general research on pedagogy has demonstrated that a variety of teaching models can be effective, and that some styles are more effective for certain types of material and for particular kinds of learners therefore, beyond understanding how men and women faculty teach differently, it is also essential to examine whether and how gender differences may change based on 
various demographic factors. Therefore, the purpose of this study was to assess the effectiveness of male and female teachers in secondary schools with respect to different demographic factors such as marital status, training, location and medium of instruction. Understanding whether men and women teach differently is critical to assisting faculty in their efforts to improve themselves. If gender is, even in part, picking up on real differences, understanding its effect on teachers' effectiveness is important.

\section{Materials and Methods}

The present study was descriptive in nature. Target population of the study comprised of secondary school teachers from Uttar Pradesh state of India. A sample of 482 teachers including 245 (50.82\%) males and 237 (49.17\%) females working in 54 different secondary schools was drawn from the target population by purposive convenient sampling technique. The age of the participants ranged from 22 to 60 years. The participants had 1 to 38 years of teaching experience in schools.

The effectiveness variable was determined by Likert based five-point (strongly disagree, disagree, no idea, agree, strongly agree) self-rating Teacher Effectiveness Scale (TES) developed by Islahi [53]. The questionnaire TES contained 74 items aimed to evaluate teachers' classroom effectiveness in the areas of interpersonal relationship with colleagues, parents and students, classroom management, time and resource management, instructional practices, assessment of students, knowledge of subject matter, communication, diligence and dynamism. The English as well as Hindi versions of the Scale were administered along with a covering letter explaining the purpose of the survey and detailed instructions to fill up the scale. Before being used in a pilot study both versions were revised several times with the help of colleagues and experts to find out whether there was a need to modify, add or delete some items. Each teacher was to respond by reacting to the statement based on the five-point TE Scale and put a tick mark in appropriate boxes given against the items with which he/she agreed. There was no option to leave any item unanswered. The lower scores on the effectiveness scale indicated ineffective teachers and vice versa.

The Scale was distributed to the teachers of secondary level in different schools after the approval of their management. The subjects were introduced with main objectives of the study and requested to read the instructions carefully and ask the researcher if there was any difficulty in understanding the instructions. It was emphasized that no item should be omitted and that there were no correct or incorrect answers. Also there was no time limit for the scale and it was not necessary to answer all of the questions during one session.

The raw scores as obtained directly after scoring the test booklets constituted simply a long list of numbers without any order. In order to make meaningful interpretation and draw conclusions raw scores were reorganized, subjected to appropriate statistical analysis and summarized. This was achieved by using the SPSS version 12.0 statistical package.

In preliminary analysis, the internal consistency of the scale was examined. The final statements were selected after item analysis and judgmental validity. Both descriptive and inferential statistics were employed for analyzing the quantitative data.

By convention, an alpha level of .05 was established $a$ priori for determining statistical significance. Each item was assigned a weightage ranging from 5 (strongly agree) to 1 (strong disagree) for favourable items. In case of unfavourable items the scoring was reversed, i.e. from 1 (strongly agree) to 5 (strongly disagree). The effectiveness score of an individual is the sum total of item scores on all the nine areas. The range of scores is from 74 to 370 with the higher score indicating the more effectiveness and vice versa. Prior to conducting the analysis, the scoring of all negatively stated items was reversed. Cronbach's alpha of 0.953 was obtained for TES.

The analysis centred on answering the research questions. Correlation, t-test, and ANOVA were employed to evaluate the impact of gender on TE scores. ANOVA was followed by Duncan's Multiple Range Test (DMRT) where F -value was found to be significant so as to identify the trend of the difference in mean values.

\section{Results}

In order to establish the relationship between gender and teachers' effectiveness, point biserial correlation was calculated between teacher effectiveness and gender. Correlation $\mathrm{r}_{\mathrm{pb}}$ was found to be insignificant $\left(\mathrm{r}_{\mathrm{pb}}=0.039, p\right.$ $>0.05$ ) which indicates that in the present study gender had no significant influence on overall effectiveness of secondary school teachers.

Overall TE scores of male and female teachers were subjected to student's t-test (Table 1). Though male participants recorded slightly higher mean scores than females, there was no significant difference $(p>0.05)$ between effectiveness of male and female teachers.

One-way ANOVA of the average effectiveness scores of male and female teachers with respect to their location (rural/urban) have been presented in Table 2. Results revealed that there were no significant differences $(p>0.05)$ in the effectiveness of the groups: rural male, urban male, rural female and urban female teachers. 
Table 1. Difference in effectiveness of male and female teachers

\begin{tabular}{|c|c|c|c|c|c|c|c|}
\hline & $\mathrm{N}$ & Mean & $\begin{array}{c}\text { Std. } \\
\text { Deviation }\end{array}$ & Std. Error Mean & $\mathrm{df}$ & $\mathrm{t}$ & Significance \\
\hline Male & 245 & 232.2980 & 55.41843 & 3.54055 & \multirow{2}{*}{480} & 0.630 & Not Significant \\
\cline { 1 - 5 } Female & 237 & 229.0675 & 57.13955 & 3.71161 & & \\
\hline
\end{tabular}

Table 2. Effectiveness of teachers with respect to their location

\begin{tabular}{|c|c|c|c|c|c|}
\hline & Sum of Squares & df & Mean Square & F & Significance \\
\hline Between Groups & 10488.427 & 3 & 3496.142 & & \\
\cline { 1 - 4 } Within Groups & 1510664.909 & 478 & 3160.387 & \multirow{2}{*}{1.106} & 346 \\
\hline Total & 1521153.336 & 481 & & \\
\hline
\end{tabular}

Table 3. Effectiveness of teachers with respect to their training

\begin{tabular}{|c|c|c|c|c|c|}
\hline \multirow{2}{*}{ Factors } & $\mathrm{N}$ & \multicolumn{2}{|c|}{ *Subset of Means for alpha =.05 } & $\begin{array}{c}\text { Standard } \\
\text { Deviation }\end{array}$ & $\begin{array}{c}\text { Standard } \\
\text { Error }\end{array}$ \\
\cline { 3 - 6 } & 1 & 2 & 56.22231 & 5.79889 \\
\hline $\begin{array}{c}\text { Untrained } \\
\text { Female }\end{array}$ & 94 & 217.3830 & & 57.24290 & 5.81214 \\
\hline $\begin{array}{c}\text { Untrained Male } \\
\text { Trained Female }\end{array}$ & 97 & 218.5567 & 236.7483 & 56.62360 & 4.73510 \\
\hline Trained Male & 148 & & 241.3041 & 52.45570 & 4.31183 \\
\hline Sig. & & .872 & .53 & & \\
\hline
\end{tabular}

*Means in the same column are insignificantly different from each other.

Table 4. Effectiveness of teachers with respect to their marital status

\begin{tabular}{|c|c|c|c|c|c|c|}
\hline \multirow{2}{*}{ Factors } & \multirow{2}{*}{$\mathrm{N}$} & \multicolumn{3}{|c|}{$*$ Subset of Means for alpha $=.05$} & \multirow{2}{*}{$\begin{array}{c}\text { Standard } \\
\text { Deviation }\end{array}$} & \multirow{2}{*}{$\begin{array}{c}\text { Standard } \\
\text { Error }\end{array}$} \\
\hline & & 1 & 2 & 3 & & \\
\hline Married Female & 182 & 212.4890 & & & 49.22939 & 3.64913 \\
\hline Married Male & 172 & 226.5116 & & & 56.98645 & 4.34518 \\
\hline Unmarried Male & 73 & & 245.9315 & & 49.26271 & 5.76576 \\
\hline $\begin{array}{c}\text { Unmarried } \\
\text { Female }\end{array}$ & 55 & & & 283.9273 & 46.41075 & 6.25802 \\
\hline Sig. & & .066 & 1.000 & 1.000 & & \\
\hline
\end{tabular}

* Means in the same column are insignificantly different from each other.

Average effectiveness scores of male and female teachers with respect to their training (trained / untrained) were found to be significantly $(p>0.05)$ different (Table 3 ). Highest TE values were observed for trained male teachers which was comparable $(p>0.05)$ to those obtained for trained female teachers. However, the TE scores of both these groups were significantly $(p<0.05)$ different from the other two groups viz., untrained male teachers and untrained female teachers. Moreover, the latter two groups were insignificantly $(p>0.05)$ different from each other.

One-way ANOVA of the average effectiveness scores of male and female teachers with respect to their marital status (married/unmarried) revealed that there were significant differences $(p<0.05)$ in TE scores of the four groups (Table 4). Lowest TE values observed for married female teachers were comparable $(p>0.05)$ to those obtained for married male teachers but significantly $(p<0.05)$ different from unmarried male and unmarried female teachers. Highest TE values observed for unmarried female teachers were significantly $(p<0.05)$ different from the other three group of teachers.

Table 5. Effectiveness of teachers with respect to their medium of instruction

\begin{tabular}{|c|c|c|c|c|c|}
\hline & $\begin{array}{c}\text { Sum of } \\
\text { Squares }\end{array}$ & df & $\begin{array}{c}\text { Mean } \\
\text { Square }\end{array}$ & F & Sig. \\
\hline $\begin{array}{c}\text { Between } \\
\text { Groups }\end{array}$ & 5550.129 & 3 & 1850.043 & & \\
\cline { 1 - 4 } Within Groups & 1515603.207 & 478 & 3170.718 & .583 & .626 \\
\cline { 1 - 4 } Total & 1521153.336 & 481 & & \\
\hline
\end{tabular}


Results of the effectiveness scores of male and female teachers with respect to their medium of instruction (English /Hindi) have been presented in Table 5. ANOVA revealed that the TE scores of different category teachers (English Male, Hindi Male, English Female and Hindi Female) were insignificantly different $(p>0.05)$ from each other.

\section{Discussion}

Effectiveness of a person in any profession directly affects his/her job performance thereby playing a decisive role in the overall organisational success. Secondary school stage plays a crucial role in the career of students. It may be considered as a kind of connecting link to the college life of the student, therefore, there is an increasing concern to study varying degrees of effectiveness of secondary school teachers. Among various factors affecting teachers' effectiveness, gender occupies an important position in case of school teachers. There is an emotional debate over the gender gap in almost all aspects of education. Gender differences in teacher effectiveness have been identified as a possible variable accounting for individual differences in teacher practice. With rapidly changing sex-ratio of school teachers, studies on the influence of gender on teachers' effectiveness have become need of the hour.

Recent years have produced many studies about the relationship between teachers' effectiveness and gender exhibiting mixed results. There are several reports corroborating our findings that, overall, gender has no influence on effectiveness of teachers [54-62]. Many researchers, however, have reported gender of teacher to be a significant predictor of effectiveness. Females were reported to be more effective teachers than their male counterparts [63-71]. On the other hand, Kulkarni [72] found that male teachers were effective whereas female teachers were average.

When different demographic factors were taken into consideration, there were some deviations from the overall gender influence. Differences in teachers' effectiveness scores of male and female teachers with respect to their training (trained/untrained) and marital status (married/unmarried) as observed in the present study could not produce gender-specific variations in overall TE scores. It has been agreed upon by educationists [73] that training has significant positive influence on effectiveness of school teachers irrespective of their gender. That is why for school teachers, pre-service training for the profession is insisted in National Policy of Education [1]. But some researchers $[59,64,66,69]$ have reported that effectiveness of trained and untrained teachers did not differ significantly. Marital status showed a very interesting trend of influence on the effectiveness of male and female teachers. Similar observations were reported by Agrawal [67] and Tyagi [74]. However, Kulkarni [72] observed that the male married teachers and female unmarried teachers were found to be more effective teachers than the male unmarried and female married teachers. On the contrary, Vijayalakshmi [59], reported that marital status did not have any significant influence on the teacher effectiveness.

In the recent past the educational system of our country has been experiencing an increasing and continuing dominance of females. This dominating trend may be observed right from student's participation and performance in school to their performance in various other sectors. However, in the existing social setup and cultural demands of a traditional country like ours the responsibilities and priorities of routine life changes drastically after marriage. Such changes are more pronounced in females than their male counterparts especially if they belong to traditional families. Even in the modern nuclear families it is the responsibility of the females to take care and manage almost all household chores either independently on their own or utilizing domestic help. This could probably be the main reason behind the sharp fall in the effectiveness of married female teachers as compared to their unmarried counterparts that exhibited highest effectiveness scores among all the categories of marital status of male and female teachers. Surprisingly, a similar trend of decrease in effectiveness was also noticed in married male teachers than their unmarried counterparts. However in case of married males, the fall in teachers' effectiveness is not as sharp as those of females as compared to their respective counterparts.

Composition of the sample is another aspect that must be taken into consideration while probing/evaluating the reasons for variations in teachers' effectiveness scores with respect to gender and marital status. In the present study we did not observe the effectiveness of the same individual male and female teachers before and after their marriage. Since sampling was done simultaneously from unmarried and married teachers of secondary schools therefore the individual composition of unmarried and married teachers was totally different. Similar explanation is true for untrained and trained teachers. There are greater chances that the degree of teachers' effectiveness of an individual may experience a decline due to social/other demographic factors but only to a certain extent; an unmarried effective teacher may remain effective even after marriage though with slightly varying degree of its effectiveness. The findings could have been more explanatory, had the same individual teachers been observed for their effectiveness before and after marriage.

Location of the school and medium of instruction could not influence the teachers' effectiveness to the extent to produce gender specific differences, which suggests that an effective teacher may remain so whether associated with rural/urban school or teaching in either Hindi/English medium of instruction. This trend is consistent with previous studies exhibiting similar outcomes $[56,61,62,64,66,75,76]$. Effectiveness of teachers, in most of the cases, may depend more on other factors than location or school context. These may include job 
satisfaction, teaching aptitude, attitude towards teaching, motivation etc. However, location of the school has been reported to affect effectiveness of teachers [77]. Teachers working in urban schools were found to be more effective than those in rural schools $[54,58,63,74]$. On the contrary, some researchers $[57,67,78]$ have reported that rural teachers were better in comparison to urban teachers with respect to their effectiveness. Singh [55] revealed that the rural female teachers had secured comparatively better scores than the rural male teachers in teacher effectiveness. Whereas Kulkarni [72] reported that rural male teachers were more effective teachers than the urban male teachers and urban female teachers were more effective teachers than rural female teachers.

Burton [79] observed that even when the abilities and performances of males and females were similar, males are seen as more able than females and so females have less access to opportunities, and leave them with less 'merit' or capacity to advance than men. Burton's comment supports the sentiments of Herkelmann et al. [80] that there is a common, unconscious ideology of women being defective or less than men. In India, historically, national leaders and male reformers promoted a limited view of female education that left the basic patriarchal social structure unchanged. Male leaders aimed to "use education to make women more capable of fulfilling their traditional roles as wives and mothers and not to make them more efficient and active units in the process of socio-economic or political development" [81]. Gandhi himself advocated culturally suitable education for women: "There is need for similar distinction between the education of males and females as has been made between them by Mother Nature herself" (cited in Agrawal and Aggarwal, [82]). Later, policies were introduced to promote the end of gender discrimination and the empowerment of women to full participation. The NPE and Programme of Action (POA) viewed education as an instrument of social transformation that would eliminate curriculum biases and enable professionals such as teachers, decision makers, administrators and planners to "play a positive interventionist role for gender equality". Yet a stark contradiction has remained between policy commitments to women's equality and actual reform. Little real change has occurred despite the clear articulation by Indian educational policy and planning of what is necessary to create democratically structured programmes that will facilitate gender sensitivity and equity. The recruitment and promotion of teachers in schools is not solely or sometimes not primarily based on the teaching effectiveness. In certain quarters such as physical education (sports), excursions and tours, conducting examinations, maintaining law and order, and management, males almost always get preference over their counterparts by the school management in spite of comparable qualifications. This study is a curtain raiser to the disbelief in developing countries regarding the abilities of the female teachers and it asserts that in the changing society of the $21^{\text {st }}$ century the fairer sex is in no way a weaker teacher but equally good or even stronger in being an effective teacher.

\section{Conclusion and Implications}

It may be concluded that if different demographic factors are not given individual consideration then gender does not seem to influence the effectiveness of secondary school teachers. Effective teachers may come from diverse backgrounds. Marital status and training appear to affect the effectiveness of male and female teachers; marriage showing a negative impact while training a positive impact on effectiveness irrespective of gender. However, further researches on similar lines are warranted in order to produce more conclusive information by taking long-term studies involving the same individuals.

Results of the present investigation help in our understanding of gender-related influences in Indian schools and could be the basis for increasing educators' awareness and knowledge of the various ways that gender-role stereotypes affect their own perceptions, interactions, and expectations. The study has revealed that the teachers need to have basic teaching skills as a part of their repertoire of effectiveness. For this, pre-service training of school teachers should be stressed. Moreover, modules for development of teaching skills need to be developed. In-service training and orientation programs may be organized by the school authorities to make teaching more effective. Teacher training programmes and seminars for teachers and administrators may focus on the discussion of ways to help them overcome rigid concepts of gender roles in their daily practice and acquire more flexible gender-role beliefs and behaviour. The programs may consist of elements such as effective and active teaching and learning; evaluation on learning and teaching progress; leadership skills; e-learning skills; academic guidance; effective communication in a workplace and with students; creative thinking; duty, time and stress management; and supervision skills. There should be need-based programs throughout the year concerned with personal or professional problems confronting the teachers. This appears warranted in view of the findings that marriage as well as training influences the degree of teachers' effectiveness. The outcome of our research also suggests that effective teachers cannot be judged by the location of school or medium of instruction. Emphasis should be given to sharpen areas other than the location of school or medium of instruction in order to make teaching more effective. Also, in general there should never be any kind of pre-notion regarding gender-specific, school location-specific and medium of instruction-specific effectiveness of secondary school teachers.

Assuming gender as an important predictor of abilities, skills and interests of an individual is erroneous. Such ways of categorizing gender often lead to gender hierarchies and injustices for whole groups as well as individuals [83]. While there may be broad gender trends, these are trends 
only; they should not be interpreted as generalised rules. Any differences exhibited should be regarded as some cultural, societal or situational influences and experiences of the genders which should be further investigated and used synergistically to improve professional service.

\section{Acknowledgements}

Authors are thankful to Dr. M. Afzal Khan, Assistant Professor, Department of Zoology, AMU, Aligarh for critically going through the manuscript and assisting in the statistical analysis of the data. This study forms part of the doctoral dissertation of the first author. Financial help rendered by the University Grants Commission, New Delhi in the form of UGC Non-NET fellowship to the first author is also acknowledged.

\section{REFERENCES}

[1] National Policy on Education (NPE). Ministry of Human Resource Development, New Delhi, Government of India, 1986 (modified in 1992).

[2] Evangeline F. Golla and Estefania S. de Guzman. "Teacher Preparation in Science and Mathematics Education: A Situation Analysis". Science Education in the Philippines: Challenges for Development. Quezon City: NSEC, 1998.

[3] W.W. Miller, A.A. Kahler, and K. Rheault. Profile of the Effective Vocational Agriculture Teacher. The Journal of Agricultural Education, 30 (2), 33-40, 1989.

[4] E. Hanushek. Teacher Characteristics and Gains in Student Achievement: Estimation using Micro Data. American Economic Review, 61(2), 280-288, 1971.

[5] M. Daniel. Measuring teacher effectiveness: Some methodology reflection. Educational Research and Evaluation, 12 (1), 53-74, 2006.

[6] R.F. Lusch and M. O'Brien. Fostering Professionalism. Marketing Research, 9 (1), 24-30, 1997.

[7] J.J. Shestack. Taking Professionalism Seriously. $A B A$ Journal, 84(8), 70, 1998.

[8] P. Munoz, R. Carmen, E. Pacheco, R. Fernandez and Baltasar. The Ideal Teacher: Implications for Student Evaluation of Teacher Effectiveness. Assessment \& Evaluation in Higher Education, 25 (3), 253-263, 2000.

[9] F. Analoui. Teachers as Managers: An Exploration into Teaching Styles. International Journal of Educational Management, 9 (5), 16-19, 1995.

[10] Hargreaves and M. Fullan. Mentoring in the New Millennium: Theory into Practice. 39 (1), 50-56, 2000.

[11] Thomas F. Nelson Laird, Gender Gaps: Understanding teaching style differences between men and women. Internet resources. 2007. Retrieved on October 15, 2013, from http://cpr.iub.edu/uploads/2007AIRGenderGaps.pdf
[12] S.A. Basow. Student Evaluations: The Role of Gender Bias and Teaching Styles. In L.H. Collins, J.C. Chrisler, \& K. Quina (Eds.). Career Strategies for Women in Academe: Arming Athena (pp. 135-156). Thousand Oaks. CA: Sage 1998.

[13] Jelena Zivkovic, Apkar Salatian, Fatima Ademoh, Lawrence Oborkhale, Perceptions of Male and Female Lecturers at an American Style University in Nigeria, International Journal of Academic Research in Business and Social Sciences, 2(5), 2012.

[14] Whitworth, J. E., B. A. Price, and C. H. Randall. "Factors That Affect College of Business Student Opinion of Teaching and Learning." Journal of Education for Business May/June: 282-89, 2002.

[15] T.L. Good, J.N. Sikes and J.E.Brophy. Effects of teacher sex and student sex on classroom interaction. Journal of Educational Psychology, 65 (1), 74-87, 1973.

[16] F.A. Maher. Toward a Richer Theory of Feminist Pedagogy: A Comparison of "Liberation" and "Gender" Models for Teaching and Learning. Journal of Education, 169 (3), 91-100, 1987.

[17] Nasser Rashidi, Sahar Naderi. The Effect of Gender on the Patterns of Classroom Interaction , Education 2(3), 30-36, 2012.

[18] Tracy Darrin Wood, Teacher Perceptions of Gender-Based Differences among Elementary School Teachers, International Electronic Journal of Elementary Education, 4(2), 317-345, 2012.

[19] Earl E. McDowell. "An Exploratory Study of GTA's Attitudes Toward Aspects of Teaching and Teaching Style." Paper presented at the Annual Meeting of the Speech Communication Association (Miami Beach). (ERIC Document Reproduction Service No. ED 370 147), 1993.

[20] C.H. Lacey, A. Saleh, and R. Gorman. Teaching Nine To Five: A Study Of The Teaching Styles Of Male And Female Professors. Paper presented at the Annual Women in Education Conference, Lincoln, Nebraska, October 11-12. (Eric No. ED442334), 1998.

[21] A.Statham, L.Richardson, and J. A. Cook. Gender and university teaching: A negotiated difference. Albany, State University of New York Press, 1991.

[22] Y.M. Chen. Feminization in writing pedagogy: A study of teacher's gender at EFL university composition classrooms. Research Report, Taiwan: National Chung Cheng University. (ERIC Document Reproduction Service NO. ED462847), 2000 .

[23] M. Chavez. Teacher and student gender and peer group gender composition in German foreign language classroom discourse: An exploratory study. Journal of Pragmatics, 32, 1019-1058, 2000.

[24] A. Chudgar and V. Sankar. The relationship between teacher gender and student achievement: Evidence from five Indian states. A Journal of Comparative Education, 38(5), 627-642, 2008.

[25] G. H. Starbuck. College teaching styles by gender. Paper presented at the Annual Meeting of the Western Social Science Association, Las Vegas, NV, 2003. 
[26] C. E. Brawner, R. M. Felder, R. Allen, and R. Brent. 1999-2000 SUCCEED faculty survey of teaching practices and perceptions of institutional attitudes toward teaching. Gainesville, FL: Southeastern University and College Coalition for Engineering Education, 2001.

[27] E. Singer. Espoused Teaching Paradigms Of College Faculty. Research in Higher Education, 37 (6), 659-679, 1996.

[28] W. J. Lammers, and J. J. Murphy. A profile of teaching techniques used in the university classroom: A descriptive profile of a U.S. public university. Active Learning in Higher Education, 3 (1), 54-67, 2002.

[29] T. F. Nelson Laird, A. K. Garver, and A. S. Niskode. Gender gaps: Understanding teaching style differences between men and women. Paper presented at the Annual Meeting of the Association of Institutional Research, Kansas City, MO, 2007.

[30] D. Tannen. You just don't understand. New York: Virago Press, 1992.

[31] P. Marchbanks. Personality traits: Elementary school teachers-prospective elementary school teachers: Are they out there? , 2000. Retrieved on January 6, 2009, from http://www.unc.edu/courses/2004spring/engl/012/054/PDF\% 20files/Sample\%20Papers/Unit\%202\%20Project/Unit\%202-teacher.pdf

[32] D. J. Smith. The Use and Perceived Effectiveness of Instructional Practices In Two-Year Technical Colleges. Unpublished doctoral dissertation, The University of Georgia, Athens, 2010.

[33] B. Sandler, L.A.Silverberg, and R. M. Hall. The chilly classroom climate: A guide to improve the education of women. Washington D.C.: National Association for Women in Education, 1996.

[34] M.B.A. Doray. Gender differentiated discourse: A study of teacher discourse in the adult ESL classroom. 2005. Retrieved on October 21, 2013, from http:// espace.library. cur-tin.edu.au $/$ R? func $=$ dbin-jump-full\&object_id=16608\&local_base=GEN01-ER A02

[35] N. Rashidi and M. Rafiee Rad. Analyzing patterns of classroom interaction in EFL classrooms in Iran. The Journal of Asia TEFL, 7(3), 93-120, 2010.

[36] J. Brophy. Interactions of male and female students with male and female teachers. In L.C. Wilkinson \& C.B. Marrett (Eds), Gender influences in classroom interaction (pp. 115-142). New York: Academic Press, 1985.

[37] J. L. Meece. The influence of school experiences on the development of gender schemata. In L. S. Liben \& M. L. Signorella (Eds.), Children's gender schemata (pp. 57-73). San Francisco, CA: Jossey-Bass, 1987.

[38] S.A., Basow, and N.T. Silberg. Student Evaluations of College Professors: Are Female and Male Professors Rated Differently. Journal of Educational Psychology, 79, 308-314, 1987.

[39] S.A. Basow, and M.S. Distenfeld. Teacher Expressiveness: More Important for Males than Females? Journal of Educational Psychology, 77, 45-52, 1985.

[40] D. Kierstead, P. D' Agostino, and H. Drill. Sex Role stereotyping of College Professors: Bias in Students Ratings of Instructors. Journal of Educational Psychology, 80, 342-344, 1988

[41] K. Andersen and E.D. Miller. Gender and student evaluations of teaching. Political Science \& Politics, 30, 216-219, 1997.

[42] A.L. Burns-Glover, and D.J. Veith. Revisiting gender and teaching evaluation. Sex still makes a different. Journal of Social Behavior \& Personality: Special Issue: Gender in the workplace, 10 (6), 69-80, 1995.

[43] M. S. Kimmel. The Gendered Society. New York: Oxford University Press, 2000.

[44] M. E. Kite. Gender stereotypes. In J. Worell (Ed.), Encyclopedia of Women and Gender (Vol. 1, pp. 561-570). San Diego: Academic Press. 2001.

[45] B. B. Zigmund. The well-being of women is still being sabotaged-by colleagues, by students, and by themselves. Chronicle of Higher Education, p. A44 (1988, Sept. 1).

[46] Joey Sprague and Kelley Massoni. Student Evaluations And Gendered Expectations: What We Can't Count Can Hurt Us, Sex Roles: A Journal Of Research, 53, 11-12: 779-793, 2005.

[47] L.D. Goodwin, and E.A. Stevens. The influence of gender on university faculty' members' perceptions of "good" teaching. The Journal of Higher Education, 64 (2), 166-185, 1993.

[48] R. Tieman, and B. Rankin-Ullock. 'Student evaluations of teachers', Teaching Sociology, 12, 177-91, 1985.

[49] S. Mullola, N. Ravaja, J. Lipsanen, S. Alatupa, M. Hintsanen, M. Jokela, and L. Keltikangas-Järvinen. Gender differences in teachers' perceptions of students' temperament, educational competence, and teachability. British Journal of Educational Psychology, 82, 185-206, 2012.

[50] D. Hopf and C. Hatzichristou. Teacher gender-related influences in Greek schools. British Journal of Educational Psychology, 69, 1-18, 1999.

[51] A. Kelly. 'Gender differences in teacher-pupil interactions: a meta-analytic review'. Research in Education, 39, 1-23, 1988.

[52] K. Canada, and R. Pringle. The role of gender in college classroom interactions: A social context approach. Sociology of Education, (68) 3,161-168, 1995.

[53] F. Islahi. A Study of Teaching Effectiveness of Secondary School Teachers in Relation to Their Attitude Towards Information Technology and Work Motivation. Unpublished Doctoral Dissertation. Aligarh Muslim University, 2011.

[54] D.A. Prakasham. A Study of Teacher Effectiveness as a Function of School Organizational Climate and Teaching Competency, Unpublished Doctoral Dissertation, Ravishankar Shukla University, 1986. Cited in M.B Buch (Ed). Fourth Survey of Educational Research, Vol. II, Pg 1036 .

[55] R.S. Singh. A Study of Teachers' Effectiveness and its Correlates at Higher Secondary Stage in Eastern U.P., Doctoral Dissertation. Gor. U. 1987, Cited in M.B Buch (Ed). Fourth Survey of Educational Research, Vol. II, Pg 992, (1988-92). 
[56] C. Bhasin. Teaching Aptitude and Its Relationship with Teaching Effectiveness of the Higher Secondary School Teachers In Relation To the Modern Community. Unpublished Doctoral Dissertation. Rani Durgavati Vishwavidhyalya, 1988. Cited in M.B. Buch (Ed.). Fifth Survey of Educational Research Vol. II, Pg (1988-92).

[57] K. Jayaramanna. A Study of Teacher Effectiveness in Relation to Work Orientation and Achievement of Students at Primary Level. Doctoral Dissertation. Andhra University, 2001.

[58] Kagathala, A.B., A Study Of Effectiveness Of Teachers Of Secondary Schools In Gujarat. Journal of Education and Psychology. 59(4) and 60(1), 26-33, 2002

[59] Vijayalakshmi, G., Factors effecting teacher effectiveness. EduTracks 1(5), pp. 35-38, 2002.

[60] Mohanty S.K. and Parida A.K., Teacher Effectiveness of Secondary School Teachers in Relation to their Self Concept, Gender and type of institutions- A Study, MERI-Journal of education, 5(1), 2010.

[61] Ritu and A. Singh, A Study of Teaching Effectiveness of Secondary School Teachers in Relation to their Demographic Variables, International Journal of Innovative Research \& Development, 1(6), 97-107, September 2012

[62] N. Baraiya and N.C. Baraiya, The Relationship Between High School Teachers' Quality And Students Achievement, International Journal Of Humanities And Social Science Invention, 2(9), 50-54, 2013.

[63] S.L. Sofat. Construction and Standardization of Self Evaluation Scale of Teaching Effectiveness of Secondary School Teachers, Fourth Survey of Educational Research, Vol. II, Pg 1041, 1977.

[64] T. Singh. A Study of Teaching Efficiency In Relation To Job Satisfaction and Socio-Economic Status of Secondary School Teachers. Doctoral Dissertation. Avadh University, 1988. Cited in M.B Buch (Ed). Fifth Survey of Educational Research, Vol. II, Pg 1489, (1988-92).

[65] P.C. Biswas, and T. De. A Survey on Effectiveness of Secondary School Teachers in Tripura. Indian Journal of Psychometry and Evaluation, 26 (I), 17-24, 1995.

[66] G. Yadagiri. A Comparative Study of Professional Attitudes and Teacher Effectiveness Among Physical Science Teachers of Ranga Reddy and Medak Districts of Andhra Pradesh. Ph.D. Education, Osmania University, 2000.

[67] R. Agrawal. Social Intelligence and Teacher Effectiveness. Unpublished Doctoral Dissertation. Bundelkhand University, 2003.

[68] S.A. Arokiadoss. Teacher Effectiveness of College Teachers. Perspectives in Education, 21(2), 106-116, 2005.

[69] A. Kalita, A study on managing effectiveness of secondary school teachers in Guwahati city, India, The Clarion, 1 (2), 238-241, 2012

[70] Surajit Mahanta, Professional Competence VIS-À-VIS Variations of Gender and Locality, International Journal of Scientific and Research Publications, 2(12), 1-3, 2012.

[71] Thomas F.Luschei, The Effectiveness And Distribution Of Male Primary Teachers: Evidence From Two Mexican States, International Journal Of Educational Development, 32(1), $145-154,2012$

[72] A.H. Kulkarni. A Comparative Study of Male and Female Secondary School Teachers with respect to their Personality Traits, Competency and Teaching Effectiveness. Doctoral Dissertation. Shivaji University, 2000.

[73] Fazalur Rahman et al., Relationship between Training of Teachers and Effectiveness Teaching, International Journal of Business and Social Science, 2(4), 150-160, 2011.

[74] Shweta Tyagi, A Study of Teaching Effectiveness of Secondary School Teachers in Relation to their Demographic Characteristics, International Journal of Engineering and Innovative Technology (IJEIT), 3(1), 288-295, 2013.

[75] U. Gupta. Job Involvement And Need Patterns Of Primary School Teachers In Relation To Teaching Effectiveness. Doctoral Dissertation. Allahabad University, 1981. Third Survey of Research in Education, pp 810, (1978-1983).

[76] T.J.M.S. Raju. Relationship Between Teacher Value Behavior and Teaching Competency Among the Secondary School Teachers, International Journal of Research Pedagogy and Technology in Education and Movement Sciences, 1(3),172-181, 2013.

[77] I.V.R. Reddy. A Study of Job Satisfaction and Teacher Effectiveness of Primary School Teachers. Doctoral Dissertation. Andhra University, 2001.

[78] V.D. Paul and K. Kumarvel. Teacher effectiveness: an empirical study of elementary school teachers. Experiments in Education, Vol. XXXI, No.10, 200-201, 2003.

[79] C. Burton. Redefining merit. Canberra: Australian Government Publishing Service, 1988.

[80] K. Herkelmann, T. Dennison, R. Branham, D. M. Bush, K. H. Pope, and J. P. Cangemi. Women in transition: Choices and conflicts. Education, 144 (1), 127-143, 1993.

[81] S.B. Chitnis. India. In G.P. Kelly (Ed.), International handbook of women's education. New York: Greenwood Press, 1989.

[82] S.P. Agrawal, and J.C. Aggarwal. Women's education in India. New Delhi: Concept Publishing Co, 1992.

[83] R. Connell. Gender: Short introductions. Cambridge: Polity, 2002. 